\title{
Abnormal placental cord insertion and adverse pregnancy outcomes: a systematic review and meta-analysis
}

\author{
Khadijah Irfah Ismail ${ }^{* *} \mathbb{D}$, Ailish Hannigan², Keelin O'Donoghue ${ }^{3}$ and Amanda Cotter ${ }^{1}$
}

\begin{abstract}
Background: Abnormal placental cord insertion (PCl) includes marginal cord insertion (MCl) and velamentous cord insertion ( $\mathrm{VCl}$ ). $\mathrm{VCl}$ has been shown to be associated with adverse pregnancy outcomes. This systematic review and meta-analysis aims to determine the association of abnormal PCl and adverse pregnancy outcomes.

Methods: Embase, Medline, CINAHL, Scopus, Web of Science, ClinicalTrials.gov, and Cochrane Databases were searched in December 2016 (from inception to December 2016). The reference lists of eligible studies were scrutinized to identify further studies. Potentially eligible studies were reviewed by two authors independently using the following inclusion criteria: singleton pregnancies, velamentous cord insertion, marginal cord insertion, and pregnancy outcomes. Case reports and series were excluded. The methodological quality of the included studies was assessed using the Newcastle-Ottawa Scale. Outcomes for meta-analysis were dichotomous and results are presented as summary risk ratios with $95 \%$ confidence intervals.

Results: Seventeen studies were included in the systematic review, all of which were assessed as good quality. Normal $\mathrm{PCl}$ and $\mathrm{MCl}$ were grouped together as non- $\mathrm{VCl}$ and compared with $\mathrm{VCl}$ in seven studies. Four studies compared $\mathrm{MCl}, \mathrm{VCl}$, and normal $\mathrm{PCl}$ separately. Two other studies compared $\mathrm{MCl}$ with normal $\mathrm{PCl}$, and $\mathrm{VCl}$ was excluded from their analysis. Studies in this systematic review reported an association between abnormal $\mathrm{PCl}$, defined differently across studies, with preterm birth, small for gestational age (SGA), low birthweight (<2500 g), emergency cesarean delivery, and intrauterine fetal death. Four cohort studies comparing $\mathrm{MCl}, \mathrm{VCl}$, and normal $\mathrm{PCl}$ separately were included in a meta-analysis resulting in a statistically significant increased risk of emergency cesarean delivery for $\mathrm{VCl}$ (pooled RR 2.86, 95\% Cl 1.56-5.22, $P=0.0006$ ) and abnormal PCI (pooled RR 1.77, 95\% Cl 1.33-2.36, $P<0.0001$ ) compared to normal PCl.
\end{abstract}

Conclusions: The available evidence suggests an association between abnormal $\mathrm{PCl}$ and emergency cesarean delivery. However, the number of studies with comparable definitions of abnormal PCI was small, limiting the analysis of other adverse pregnancy outcomes, and further research is required.

Keywords: Abnormal placental cord insertion, Marginal placental cord insertion, Velamentous placental cord insertion, Adverse pregnancy outcomes, Small for gestational age, Emergency cesarean delivery

\footnotetext{
*Correspondence: khadijah.ismail@ul.ie

${ }^{1}$ Obstetrics and Gynaecology Department, Graduate Entry Medical School,

University of Limerick, Limerick, Ireland

Full list of author information is available at the end of the article
} 


\section{Background}

The umbilical cord insertion site to the placenta can be described as central, eccentric, marginal (battledore), and velamentous (membranous) insertions. Central and eccentric insertions account for more than $90 \%$ of term placentas [1]. Marginal cord insertion (MCI) and velamentous cord insertions (VCI) are categorized as abnormal PCI [1]. In MCI, the cord inserts at the edge of the placenta, but still arises directly from the placental mass. In VCI, the umbilical vessels insert into the membranes, thus the vessels traverse between the amnion and the chorion before reaching the placenta. VCI occurs in approximately $1 \%$ of singleton pregnancies and MCI in approximately $7 \%[1]$.

Non-central cord insertions have been shown to modify placental functional efficiency and have a sparser chorionic vascular distribution [2]. In VCI, the umbilical vessels are prone to compression and rupture due to the lack of protection from Wharton's jelly [3]. VCI is eight times more common in twin than singleton pregnancies, with double the risk with monochorionic twins, and three times the risk in twin pregnancies with fetal growth restriction [4].

The pathogenesis of the abnormal PCI is not well understood. Three theories have been proposed: 1) The abnormal primary implantation or 'polarity theory', which postulates that umbilical cord insertion site is determined at initial implantation by the orientation of the fetal pole relative to the endometrial surface; [1] 2) The theory of trophotropism which postulates that the placenta grows in areas with good blood supply and atrophies in areas where there is not; [1] 3) The "abnormal placental development because of decreased chorionic vessel branching" theory, which posits that non-central insertion results from abnormal vasculogenesis in the placenta [5].

Some studies suggest an association between abnormal PCI and adverse pregnancy outcomes in singleton pregnancies including small for gestational age (SGA) infants, preterm birth, perinatal death, intrauterine fetal death, and intrapartum complications including emergency cesarean delivery (CD) [6-8]. There are also conflicting results where studies found that SGA infants were more commonly associated with abnormal PCI but the difference was not statistically significant $[9,10]$, and there were no differences in the risk of preterm birth and intrauterine fetal death between abnormal and normal PCI [9].

A meta-analysis published recently on placental implantation abnormalities and preterm birth found an association of VCI and adverse pregnancy outcomes such as preterm birth, SGA infants, perinatal death and neonatal intensive care unit (NICU) admission [11]. In the metaanalysis, MCI was combined with normal PCI as non-
$\mathrm{VCI}$, and pregnancies with VCI were compared to those without VCI (VCI vs. non-VCI) [11]. However, the association of MCI and adverse pregnancy outcomes has not been evaluated systematically. Therefore, our objective of conducting this systematic review and meta-analysis is to provide a summary of the observational studies on adverse pregnancy outcomes associated with MCI and VCI separately and in combination as abnormal PCI.

\section{Methods \\ Search strategy}

The Medline, Embase, CINAHL, Scopus, Web of Science, ClinicalTrials.gov, and Cochrane databases were searched on the 31 of December 2016 and include all studies available in each database from their inception to the search date. The following combination of keywords was used: (umbilical cord insertion OR cord insertion OR insertion of the cord OR placental cord insertion) AND (velamentous OR marginal OR peripheral OR battledore), (pregnancy OR labo*r OR perinatal) AND (outcome* OR complication*). The search strategy was developed with a medical librarian (Medline search strategy is included as Additional file 1). It was adapted separately for each database. No language filters were applied. Reference lists of the eligible studies were scrutinized to identify further studies. The search strategy was pre-defined prior to the search but no protocol and the review was not registered with PROSPERO.

\section{Study selection}

Potentially eligible studies identified from the database including conference abstracts were reviewed by two authors (KII and $\mathrm{AC}$ ) independently using the following inclusion criteria: singleton pregnancies, $\mathrm{VCI}, \mathrm{MCI}$, and pregnancy outcomes. Discrepancies were resolved by reaching consensus between the reviewers. Multiple pregnancies were excluded due to the higher prevalence of abnormal PCI and higher risk of adverse outcomes in these pregnancies compared to singleton pregnancies. At least one of the pregnancy outcomes was reported in selected studies. Case reports and case series were excluded. Multiple articles based on the same data were only included once. Data from the same setting but with non-overlapping study periods were included.

Outcomes examined in this systematic review were small for gestational age (SGA) infants defined as birth weight less than the tenth centile for the gestation, emergency $C D$, intrauterine fetal death which refers to babies born after 24 weeks gestation or birth weight of more than $500 \mathrm{~g}$, with no signs of life; preterm birth where the gestational age at birth was less than 37 completed weeks, low birth weight defined as birth weight of less than $2500 \mathrm{~g}$, postpartum hemorrhage defined as blood loss of more than $500 \mathrm{ml}$, and manual removal of 
placental (retained placenta needing removal manually in operating theater. Meta-analysis was planned on cohort studies where the same outcomes were examined for MCI and VCI were separately, with MCI defined as distance from PCI site to the placental margin of less than two centimeters. Studies not fitting the criteria for meta-analysis were included in the descriptive analysis.

\section{Methodological quality assessment}

Methodological quality of the eligible studies was assessed by KII using the Newcastle-Ottawa Scale [12]. The studies were assessed based on the representativeness of the exposed cohort, selection of the non-exposed cohort, ascertainment of exposure, comparability of cohorts on the basis of the design and analysis and assessment of outcome. Using an adapted GRADE framework [13], we rated the quality of evidence across studies (with comparable definitions of abnormal PCI) for each primary outcome as high, moderate, low, or very low based on factors such as study design and limitations, inconsistency in study findings, and imprecision.

\section{Data collection}

Data were extracted using a data extraction form and recorded in a Microsoft Excel spreadsheet. The information obtained from each article includes study design, participants' characteristics, definition of abnormal PCI used and the pregnancy outcomes compared.

\section{Data analysis}

The systematic review was reported in accordance to the Preferred Reporting Items for Systematic Reviews and Meta-Analyses (PRISMA) guideline. The completed PRISMA checklist is included as Additional file 2. For meta-analysis, all outcomes were dichotomous and results are presented as summary risk ratios with 95\% confidence intervals. Heterogeneity was assessed using the $x^{2}$ test and the inconsistency index- $I^{2}$ statistic. A random effects model was used where there was evidence of significant heterogeneity ( $p$ value from the $\chi^{2}$ test $<0.10$ or $\left.I^{2}>40 \%\right)$. A fixed effects model was used where there was no evidence of heterogeneity. The Egger test and funnel plot were used to assess publication bias. Analysis was carried out using Review Manager Software REVMAN Version 5.3. For outcomes where meta-analyses could not be performed, a descriptive synthesis was carried out.

\section{Results}

\section{Literature search}

A total of 2732 articles were identified through database searching and from scrutinizing the eligible articles. After screening the title and abstract, 2698 articles were excluded. Thirty-four full-text articles were then assessed. Seventeen further articles were excluded after detailed reading, leaving 17 articles for data extraction and descriptive synthesis. Four studies were included for quantitative analysis (see PRISMA flow diagram Fig. 1). The details of included studies in the qualitative and quantitative analyses are presented in Table 1, and those of excluded studies, in Additional file 3.

\section{Study characteristics}

Twelve of the included studies were cohort studies and five were case-control studies (Table 1). PCI was categorized based on gross examination in three studies [14-16], from ultrasound examination in two studies $[17,18]$, or from secondary analysis of existing databases in the other 12 studies (Table 1). Comparison groups were also different in the 17 included studies. Only five studies compared $\mathrm{MCI}, \mathrm{VCI}$, and normal PCI $[6,14,16,18,19]$. Seven studies compared VCI and non-VCI pregnancies $[7,8,10,15,20-22]$. Two studies compared only $\mathrm{MCI}$ and normal $\mathrm{PCI}$, excluding $\mathrm{VCI}$ $[17,23]$. Boulis et al. compared outcomes of pregnancies with MCI and VCI with outcomes for the general population from the Centers for Disease Control and Prevention (CDC) database [24]. Two other studies compared central PCI with peripheral PCI but using different definitions for peripheral PCI $[9,25]$.

\section{Methodological quality}

The assessment of the methodological quality of included studies, based on the Newcastle-Ottawa Scale, is given in Table 2. The majority of included studies were considered good quality with the cohort being representative of the population and both normal and abnormal PCI selected from the same population. The adverse outcomes were identified at the start of the study, were assessed independently, and the assessment of normal and abnormal PCI was ascertained from ultrasound, gross examination, or medical records in all included studies. Ten studies adjusted for known confounders such as maternal age, parity, and maternal smoking in a multivariable regression analysis $[6-8,10,15,16,20-22,25]$. Five studies $[9,14,17,23,24]$ had insufficient information to assess adjustment for confounders (four of those studies $[14,17,23,24]$ were conference abstracts).

The lack of a comparable definition of abnormal PCI used across all studies limited the GRADE assessment of the evidence for each adverse pregnancy outcome. Only the evidence for one outcome, emergency $\mathrm{CD}$, was assessed (Table 3).

\section{Meta-analysis}

We found only three cohort studies comparing MCI, VCI, and normal PCI separately and all were included in the meta-analysis $[14,18,19]$. Another study by 


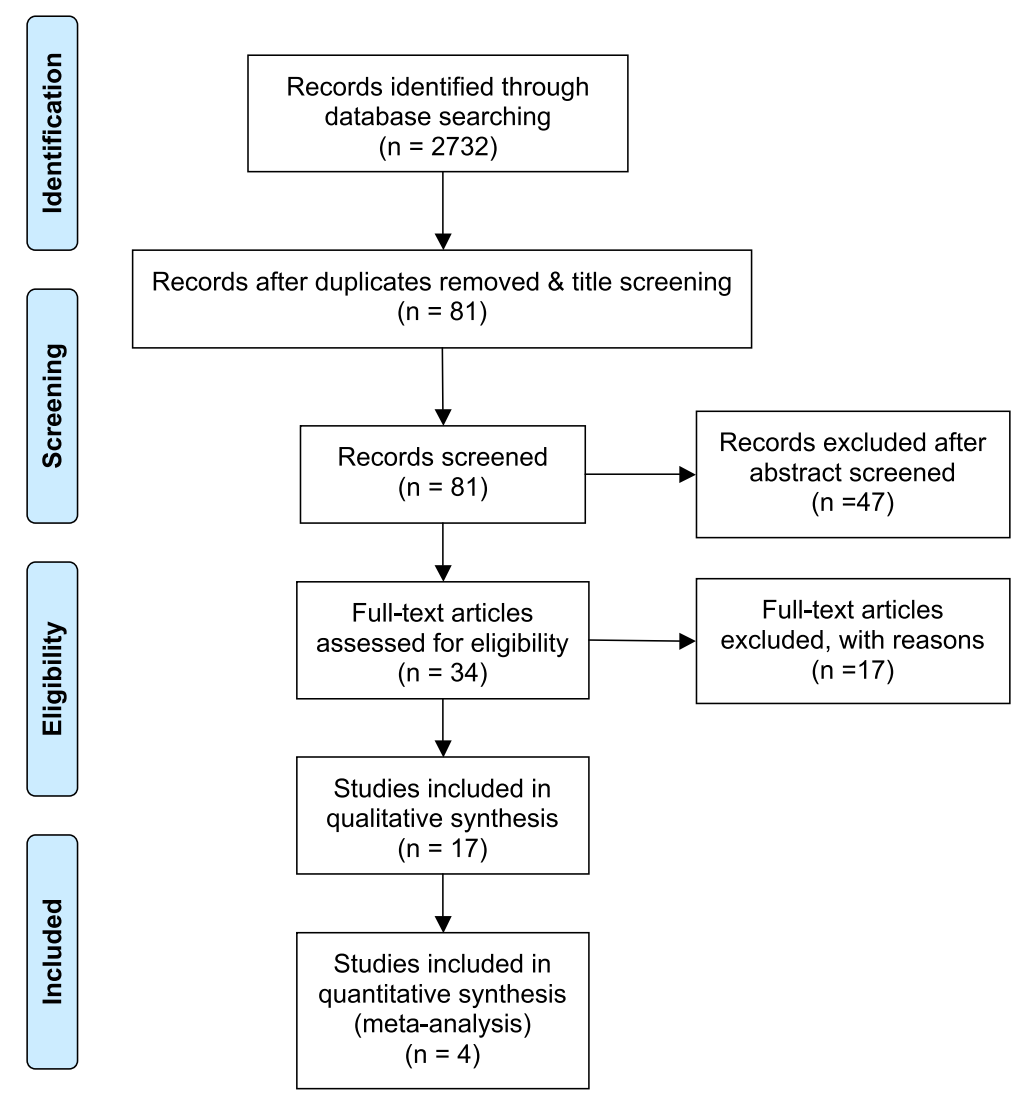

Fig. 1 Flow diagram of search results. Based on the Preferred Reporting Items for Systematic Reviews and Meta-analyses (PRISMA) flow diagram

Ebbing et al. made two different comparisons, where MCI were compared with non-MCI (VCI included) and VCI were compared to non-VCI (MCI included) [6]. We calculated $\mathrm{MCI}$ and $\mathrm{VCI}$ data separately from the tables in the article. MCI was defined as distance of PCI to placental margin of less than $2 \mathrm{~cm}$ in all included studies. The only outcome available to be examined from these studies $[6,14,18,19]$ was emergency CD.

An increased risk of emergency CD was observed for VCI (pooled RR 2.86, 95\% CI 1.56-5.22, $P=0.0006$ ) compared to normal PCI. There was evidence of significant heterogeneity $\left(\chi^{2}=11.35, P=0.01, I^{2}=74 \%\right)$ and a random effects model was used (Fig. 2). The quality of evidence was assessed as moderate.

When VCI and MCI were combined together as abnormal PCI and compared with normal PCI, a similar pattern was found. Abnormal PCI was also associated with an increased risk of emergency $\mathrm{CD}$ (pooled RR $1.77,95 \%$ CI 1.33-2.36, $P<0.0001$ ). There was some evidence of heterogeneity $\left(\chi^{2}=5.35, P=0.15, I^{2}=44 \%\right)$, and a random effects model was used (Fig. 2). The quality of evidence was assessed as moderate.

A meta-analysis of the four studies comparing the risk of emergency $\mathrm{CD}$ for $\mathrm{MCI}$ to normal $\mathrm{PCI}$ is not presented as Ebbing et al. [6], due to the very large sample size, dominated the results with a weight of over $99 \%$. In two of the studies $[6,14]$, MCI was associated with an increased risk of emergency $\mathrm{CD}$. The size of the MCI group was small in the other two studies $[18,19]$ with wide confidence intervals for risk of emergency $C D$.

\section{Descriptive synthesis}

Of the 17 studies included in the systematic review, 13 studies were excluded from the meta-analysis. Five studies were excluded from the meta-analysis as they did not have separate data for $\mathrm{MCI}$ and the comparison of pregnancy outcomes was only made between $\mathrm{VCI}$ and non-VCI with $\mathrm{MCI}$ included in the non-VCI group $[7,8,10,20,21]$. All five studies reported an increased risk of preterm birth in the VCI group $[7,8,10,20,21]$. Four of those studies also reported an increased risk of SGA [7, 8, 20, 21]. VCI was also noted to have an increased risk of labor complications such as postpartum hemorrhage $(6.66 \%$ vs. $2.88 \%, P=0.001)$ and manual removal of placenta $(14.47$ vs. $0.76 \%, P=0.01)$ compared with non-VCI [7]. Only one of the five studies reported an increased risk of emergency $\mathrm{CD}$ in VCI compared to non-VCI $(15.3$ vs. $8.3 \%, P \leq 0.001)[8]$.

Two studies were excluded due to variation in the definition of MCI $[9,25]$. Uyanwah-Akpom et al. defined 
Table 1 Characteristics of included studies

\begin{tabular}{|c|c|c|c|c|c|c|c|}
\hline Study & $\begin{array}{l}\text { The setting } \\
\text { (center) }\end{array}$ & $\mathrm{PCl}$ categorization & Design & $\begin{array}{l}\text { Comparison } \\
\text { groups }\end{array}$ & $\begin{array}{l}\text { No of } \\
\text { participants }\end{array}$ & Study Duration & Outcomes \\
\hline Burke 2011 [14] & $\begin{array}{l}\text { Maternity Unit, } \\
\text { University Maternity } \\
\text { Hospital, Limerick, Ireland }\end{array}$ & $\begin{array}{l}\text { Gross } \\
\text { examination }\end{array}$ & $\begin{array}{l}\text { Prospective } \\
\text { cohort }\end{array}$ & $\begin{array}{l}\mathrm{MCl}, \mathrm{VCl} \text { vs. } \\
\text { normal PCl }\end{array}$ & 727 & not specified & SGA, Em CD \\
\hline Boulis 2013 [24] & $\begin{array}{l}\text { Obstetrics Dept, } \\
\text { LIJ School of Medicine, } \\
\text { Long Island, } \\
\text { New York, USA }\end{array}$ & Existing data & $\begin{array}{l}\text { Retrospective } \\
\text { cohort }\end{array}$ & $\begin{array}{l}\mathrm{MCl}, \mathrm{VCl} \text { vs. } \\
\mathrm{CDC} \text { database }\end{array}$ & 122 & 2002-2012 & $\begin{array}{l}\text { PTB, SGA, } \\
\text { Em CD, IUFD }\end{array}$ \\
\hline Brouillet 2014 [25] & $\begin{array}{l}\text { Obstetrics Dept, } \\
\text { Grenoble University } \\
\text { Hospital, France }\end{array}$ & Existing data & $\begin{array}{l}\text { Retrospective } \\
\text { cohort }\end{array}$ & $\begin{array}{l}\text { Central PCI vs. } \\
\text { Peripheral (MCl, VCl } \\
\text { and paracentral PCI) }\end{array}$ & 528 & $\begin{array}{l}\text { Aug } 2006 \text { - } \\
\text { Dec } 2006\end{array}$ & SGA \\
\hline Carbone 2008 [23] & $\begin{array}{l}\text { Obstetrics Dept, } \\
\text { Hartford Hospital, } \\
\text { Connecticut, USA }\end{array}$ & Existing data & Case-control & $\mathrm{MCl}$ vs. normal $\mathrm{PCl}$ & 282 & $\begin{array}{l}\text { Nov } 2005 \text { - } \\
\text { Feb } 2008\end{array}$ & PTB \\
\hline Ebbing 2013 [6] & $\begin{array}{l}\text { Medical Birth } \\
\text { Registry of Norway }\end{array}$ & Existing data & $\begin{array}{l}\text { Retrospective } \\
\text { cohort }\end{array}$ & $\begin{array}{l}\mathrm{VCl} \text { vs. non- } \mathrm{VCl} \text {, } \\
\mathrm{MCl} \text { vs. non-MCl }\end{array}$ & 634,741 & 1999-2009 & $\begin{array}{l}\text { PTB, SGA, } \\
\text { Low BW, } \\
\text { Em CD, IUFD }\end{array}$ \\
\hline Eddleman 1992 [10] & $\begin{array}{l}\text { Obstetrics Dept, } \\
\text { The Mount Sinai } \\
\text { School of Medicine, } \\
\text { New York, USA }\end{array}$ & Existing data & $\begin{array}{l}\text { Retrospective } \\
\text { cohort }\end{array}$ & VCl vs. non-VCl & 15,942 & $\begin{array}{l}\text { Jan } 1985- \\
\text { Dec } 1988\end{array}$ & $\begin{array}{l}\text { PTB, SGA, } \\
\text { Low BW }\end{array}$ \\
\hline Esakoff 2015 [7] & California Birth Statistics & Existing data & $\begin{array}{l}\text { Retrospective } \\
\text { cohort }\end{array}$ & $\mathrm{VCl}$ vs. non- $\mathrm{VCl}$ & 482,812 & $\begin{array}{l}\text { Jan } 2006 \text { - } \\
\text { Dec } 2006\end{array}$ & $\begin{array}{l}\text { PTB, SGA, } \\
\text { Em CD, IUFD }\end{array}$ \\
\hline Feldman 2004 [17] & $\begin{array}{l}\text { Obstetrics Dept, } \\
\text { Hartford Hospital, } \\
\text { Connecticut, USA }\end{array}$ & Sonography & Case-control & $\begin{array}{l}\mathrm{MCl} \text { vs. } \\
\text { normal PCl }\end{array}$ & 75 & $\begin{array}{l}\text { Jan } 2002- \\
\text { Dec } 2003\end{array}$ & $\begin{array}{l}\text { PTB, Low } \\
\text { BW, }\end{array}$ \\
\hline Hasegawa 2009 [19] & $\begin{array}{l}\text { Obstetrics Dept, } \\
\text { Showa University Hospital, } \\
\text { Tokyo, Japan }\end{array}$ & Existing data & $\begin{array}{l}\text { Retrospective } \\
\text { cohort }\end{array}$ & $\begin{array}{l}\mathrm{MCl}, \mathrm{VCl} \text { vs. } \\
\text { normal } \mathrm{PCl}\end{array}$ & 556 & $\begin{array}{l}\text { June } 2005 \text { - } \\
\text { Dec } 2006\end{array}$ & Em CD \\
\hline Hasegawa 2006 [18] & $\begin{array}{l}\text { Obstetrics Dept, } \\
\text { Showa University Hospital, } \\
\text { Tokyo, Japan }\end{array}$ & Sonography & $\begin{array}{l}\text { prospective } \\
\text { cohort }\end{array}$ & $\begin{array}{l}\mathrm{MCl}, \mathrm{VCl} \text { vs. } \\
\text { normal PCl }\end{array}$ & 3446 & $\begin{array}{l}\text { Sept } 2002 \text { - } \\
\text { June } 2004\end{array}$ & Em CD \\
\hline Heinonen 1996 [20] & $\begin{array}{l}\text { Obstetrics Dept, } \\
\text { University Hospital of } \\
\text { Kuopio, Finland }\end{array}$ & Existing data & $\begin{array}{l}\text { Retrospective } \\
\text { cohort }\end{array}$ & $\mathrm{VCl}$ vs. non-VCl & 12,750 & $\begin{array}{l}\text { July } 1989 \text { - } \\
\text { Dec } 1993\end{array}$ & $\begin{array}{l}\text { PTB, SGA, } \\
\text { Low BW, } \\
\text { Em CD, IUFD }\end{array}$ \\
\hline Pinar 2014 [15] & $\begin{array}{l}\text { Perinatal Pathology, } \\
\text { Women and infants Hospital, } \\
\text { Rhode Island, USA }\end{array}$ & $\begin{array}{l}\text { Gross } \\
\text { examination }\end{array}$ & Case-control & VCl vs. non-VCl & 1718 & $\begin{array}{l}\text { Mar } 2006 \text { - } \\
\text { Sept } 2008\end{array}$ & IUFD \\
\hline Raisanen 2012 [8] & $\begin{array}{l}\text { Obstetrics Dept, } \\
\text { University Hospital of } \\
\text { Kuopio, Finland }\end{array}$ & Existing data & $\begin{array}{l}\text { Retrospective } \\
\text { cohort }\end{array}$ & VCl vs. non-VCl & 26,849 & 2000-2011 & $\begin{array}{l}\text { PTB, SGA, } \\
\text { Low BW, } \\
\text { Em CD, IUFD }\end{array}$ \\
\hline Suzuki 2015 [21] & $\begin{array}{l}\text { Obstetrics Dept, Japanese } \\
\text { Red Cross Katsushika Maternity } \\
\text { Hospital, Tokyo }\end{array}$ & Existing data & $\begin{array}{l}\text { Prospective } \\
\text { cohort }\end{array}$ & $\mathrm{VCl}$ vs. non-VCl & 16,965 & $2002-2011$ & $\begin{array}{l}\text { PTB, SGA, } \\
\text { Em CD }\end{array}$ \\
\hline Tantbirojn 2009 [16] & $\begin{array}{l}\text { Pathology Dept, Brigham } \\
\text { and Women's Hospital, } \\
\text { Boston, MA, USA }\end{array}$ & $\begin{array}{l}\text { Gross } \\
\text { examination }\end{array}$ & Case-control & $\begin{array}{l}\mathrm{MCl}, \mathrm{VCl} \text { vs. } \\
\text { normal PCl }\end{array}$ & 541 & 1987-2007 & IUFD \\
\hline Uyanwah-Akpom 1977 [9] & $\begin{array}{l}\text { Pathology Dept, } \\
\text { St Mary's Hospital, } \\
\text { Manchester, UK }\end{array}$ & Existing data & $\begin{array}{l}\text { Prospective } \\
\text { cohort }\end{array}$ & $\begin{array}{l}\text { Normal PCI vs. } \\
\text { Peripheral PCI }\end{array}$ & 1000 & not specified & SGA, IUFD \\
\hline Yerlikaya 2016 [22] & $\begin{array}{l}\text { Obstetrics Dept, } \\
\text { Medical University } \\
\text { of Vienna, Austria }\end{array}$ & Existing data & Case-control & VCl vs. non-VCl & 216 & $\begin{array}{l}\text { Jan } 2003- \\
\text { Dec } 2013\end{array}$ & IUFD \\
\hline
\end{tabular}

$B W$ birthweight, $E m C D$ emergency cesarean delivery, IUFD intrauterine fetal death, $M C l$ marginal cord insertion, $P C l$ placental cord insertion,

PTB preterm birth, SGA small for gestational age, $V C l$ velamentous cord insertion

$\mathrm{MCI}$ as insertion at the extreme edge of the placenta, and combined it with $\mathrm{VCI}$ as peripheral cord insertion [9]. Other studies defined MCI as a PCI site of less than two centimeters from the placental margin. UyanwahAkpom et al. found an increase in the incidence of SGA in the peripheral group (5.6\%) compared to the central
(1.3\%) and eccentric (2.4\%) groups but the difference was not statistically significant [9]. They also studied the intrauterine fetal death rate between these groups, and found no difference in the intrauterine fetal death rate between the peripheral (6.9\%), central (4.1\%), and eccentric groups (6.9\%) [9]. Broulliet et al. defined paracentral 


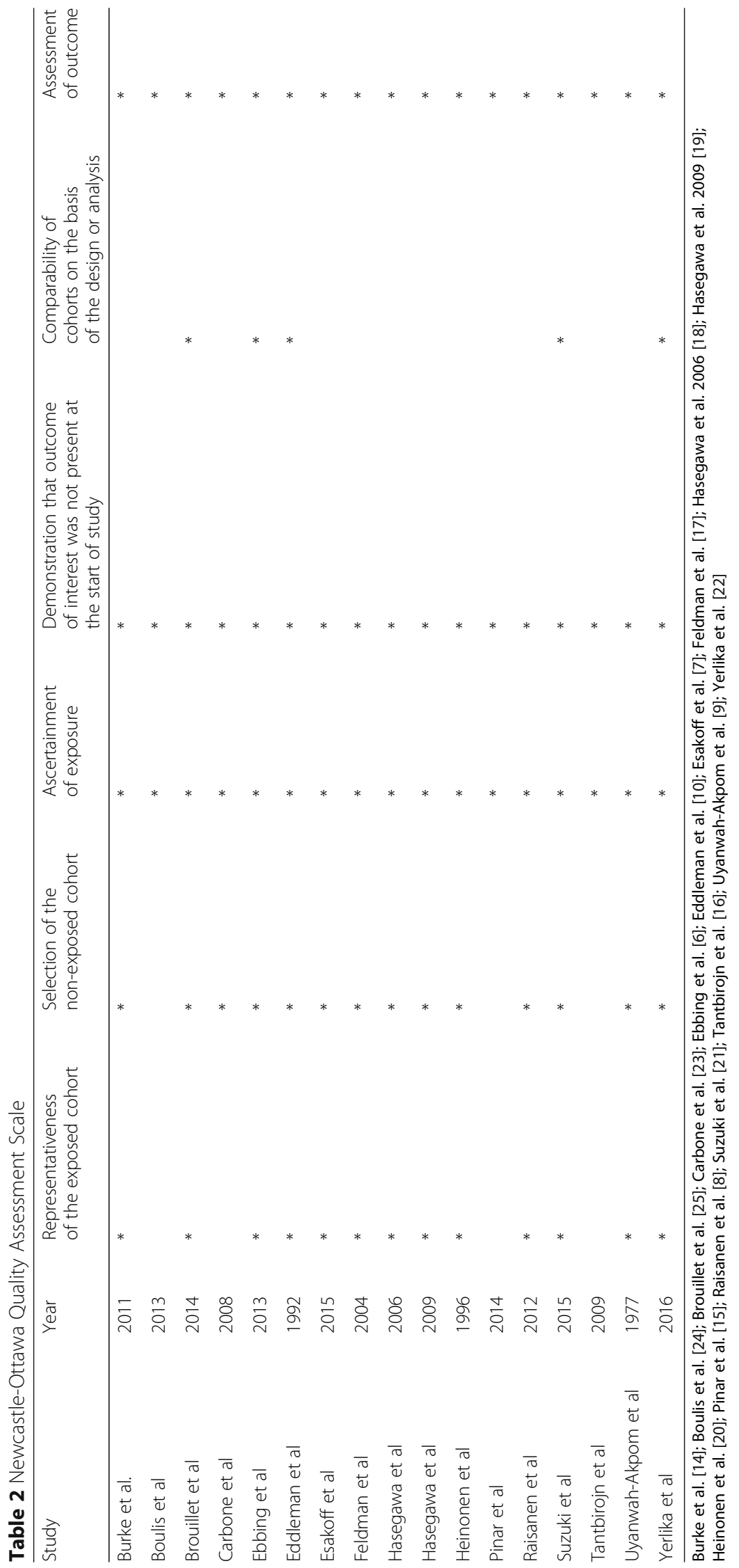


Table 3 Assessment of the outcome emergency cesarean delivery using adaptation of Grading of Recommendations Assessment, Development and Evaluation (GRADE) framework for assessing the quality of the evidence across studies

\begin{tabular}{|c|c|c|}
\hline Profile of individual studies & & Comments \\
\hline Number of studies & 4 & - References: $[6,14$, \\
\hline Number of participants & 637,438 & $\begin{array}{l}\text { - 632, } 978 \text { participar } \\
\text { Ebbing et al. [6] }\end{array}$ \\
\hline Total number of $\mathrm{VCl}$ & 9566 & \\
\hline Total number of Abnormal PCl & 49,141 & \\
\hline Total number of Normal PCl & 578,731 & \\
\hline \multicolumn{3}{|l|}{ Univariable results } \\
\hline Number of significant effect estimates $>1$ & 3 & \\
\hline Number of non-significant effect estimates & 0 & \\
\hline Number of significant effect estimates $<1$ & 1 & • Reference: [19] \\
\hline Not reported & 0 & \\
\hline \multicolumn{3}{|l|}{ Multivariable results } \\
\hline Number of significant effect estimates $>1$ & 2 & - Reference: $[6,18]$ \\
\hline Number of non-significant effect estimates & 0 & \\
\hline Number of significant effect estimates $<1$ & 0 & \\
\hline Not reported & 2 & \\
\hline \multicolumn{3}{|l|}{ Risk of diagnostic ascertainment bias } \\
\hline Very high & 0 & \\
\hline High & 0 & \\
\hline Medium & 0 & \\
\hline Low & 4 & \\
\hline
\end{tabular}

Statistical heterogeneity across studies: $P^{2}=44 \%$ (for abnormal PCl) and $P^{2}=74 \%$ (for VCl)

GRADE assessment ${ }^{a}$

Phase of investigation

GRADE criteria (based on meta-analysis)

Study limitations:

- Downgrade by -1 if most evidence is from studies with moderate or unclear risk of bias for most bias domains (serious limitations).

- Downgrade by -2 if most evidence is from studies with high risk of bias for almost all bias domains (very serious limitations).

Inconsistency: unexplained heterogeneity or variability in results across studies

- Downgrade by -1 when estimates of the risk factor association with the outcome vary in direction (for example, some effects appear protective whereas others show risk) and the confidence intervals show no, or minimal overlap.

Indirectness: the study sample, the prognostic factor, and/or the outcome in the primary studies do not accurately reflect the review question

- Downgrade by -1 when: (1) the final sample only represents a subset of the population of interest; (2) when the complete breadth of the prognostic factor that is being considered in the review question is not well represented in the available studies; or (3) when the outcome that is being considered in the review question is not broadly represented.
Comments

Phase 2 (high) • A 'high' rating was assigned before applying other GRADE criteria. All studies used cohort designs and sought to confirm the independent association between abnormal $\mathrm{PCl}$ with emergency $\mathrm{CD}$.

- All four studies had low risk of diagnostic ascertainment bias.

- No change.

- See Forest plot. There is some heterogeneity in results across studies, $(12=44 \%$ for abnormal $\mathrm{PCl}$ and $74 \%$ for $\mathrm{VCl}$.

- The confidence intervals of the four studies overlap with no change in direction noted (the $\mathrm{Cl}$ of one study included 1 [19]).

- No change.

- No change. 
Table 3 Assessment of the outcome emergency cesarean delivery using adaptation of Grading of Recommendations Assessment, Development and Evaluation (GRADE) framework for assessing the quality of the evidence across studies (Continued)

\begin{tabular}{|c|c|c|}
\hline Profile of individual studies & & Comments \\
\hline $\begin{array}{l}\text { Imprecision: } \\
\text { - Downgrade by }-1 \text { if the evidence is generated } \\
\text { by a few studies involving a small number of } \\
\text { participants and most of the studies provide } \\
\text { imprecise results. }\end{array}$ & & - No change. \\
\hline $\begin{array}{l}\text { Publication bias: } \\
\text { - Downgrade by }-1 \text { unless the value of the risk/protective } \\
\text { factor in predicting the outcome has been repetitively } \\
\text { investigated, ideally by phase } 2 \text { and } 3 \text { studies. }\end{array}$ & & - No change. \\
\hline $\begin{array}{l}\text { Moderate/large effect size: } \\
\text { - Upgrade by }+1 \text { if moderate or large similar effect is } \\
\text { reported by most studies. }\end{array}$ & & $\begin{array}{l}\text { - Three out of four studies had few events } \\
\text { resulting in wide confidence intervals for } \\
\text { effect size. } \\
\text { - No change. }\end{array}$ \\
\hline $\begin{array}{l}\text { GRADE: OVERALL QUALITY OF EVIDENCE } \\
(+, \text { very low; }++ \text {, low; }+++ \text {, moderate; }++++ \text {, high) }\end{array}$ & $\begin{array}{l}+++ \\
\text { Moderate }\end{array}$ & \\
\hline
\end{tabular}

$C D$ cesarean delivery, $P C l$ placental cord insertion, $\mathrm{VCl}$ velamentous cord insertion

${ }^{a}$ Based on adaptation 13 of GRADE evaluation framework

cord insertion as PCI of more than $3 \mathrm{~cm}$ from the center of the placenta and more than $2 \mathrm{~cm}$ from the placental margin [25]. They combined paracentral cord insertion, $\mathrm{MCI}$, and $\mathrm{VCI}$ as one group (peripheral cord insertion) [25]. Their findings showed a statistically significant increased risk of SGA in the peripheral group compared to the central group (20 versus $4.96 \%, p<0.001$ ) [25].

Five of the studies excluded from the meta-analysis were case-control studies [15-17, 22, 23]. Two were pathology-based studies on placental abnormalities $[15,16]$. Pinar et al. compared the placentas of stillborn infants (cases) with live-born infants (controls) [15]. In the study, VCI was nearly five times as common (5.0\% versus $1.1 \%$ ) among stillbirths compared to the live-born infants (OR 4.50, 95\% CI 2.18-9.27, $P<0.001)$. Tantbirojn et al. looked at the gross umbilical cord abnormalities and found an increased risk of intrauterine fetal death in VCI (cases) compared to age-matched pregnancies without any cord abnormalities (controls) $(25 \%$ versus $1.6 \%, P<0.05)$ [16].

Three other case-control studies were clinical studies [17, 22, 23]. Carbone et al. compared MCI (cases) with maternal age and gestational age-matched controls with normal PCI, and found no significant difference in the incidence of preterm birth between the groups (18.3\% versus 18.5\%, $p=0.96)$ [23]. Feldman et al. also compared MCI (cases) with maternal age and gestational age-matched controls with normal PCI and found an increased risk of preterm birth (20\% versus $5.4 \%, P=0.042)$ and lower mean birth weight, but no difference in the rate of low birth weight $(<2500 \mathrm{~g})$ [17]. Yerlika et al. compared VCI (cases) to body mass index and age-matched non-VCI (controls) and found an increased risk of fetal

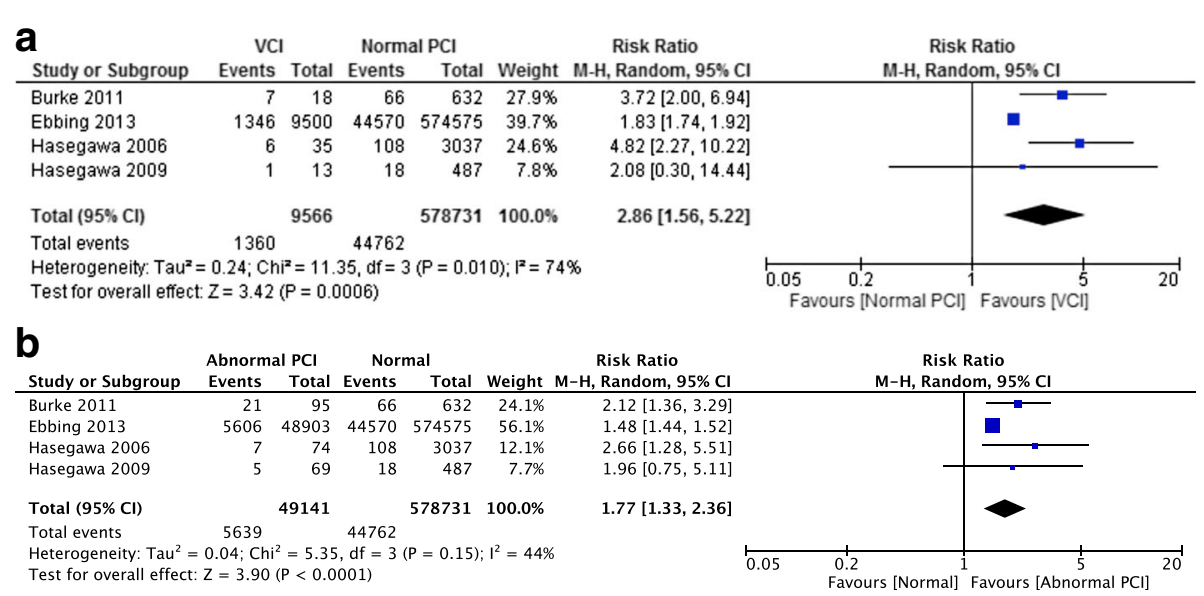

Fig. 2 Forest plot of included studies for emergency CD. a VCI vs Normal PCI. b Abnormal PCI vs Normal PCI. CD: cesarean delivery; Cl: confidence interval; PCl: placental cord insertion; VCl: velamentous cord insertion. Burke 2011 [14]; Ebbing 2013 [6]; Hasegawa 2006 [18]; Hasegawa 2009 [19] 
malformations $(12.7 \%$ versus $0 \%, P<0.001)$ and intrauterine fetal death $(6.5 \%$ versus $0 \%, P=0.014)$ [22].

Boulis et al. looked at the association of SGA with VCI and MCI as abnormal PCI group and also separately [24]. The study did not have a normal PCI group, and comparison was made with the overall SGA rate in the general population from the CDC database. They showed an increase in the incidence of SGA (31\%), preterm birth (29.51\%) and emergency CD (69.49\%) in the abnormal PCI group compared to the general population, but found no difference in the rate of intrauterine fetal death (4.1\%) [24].

Two studies examined VCI and MCI separately, and in combination as abnormal PCI $[6,14]$. An increased risk of SGA for abnormal PCI compared to normal PCI was found in both studies. Meta-analysis was not performed as Ebbing et al. [6] dominated the analysis due to its very large sample size with a weight of over $99 \%$.

\section{Discussion}

\section{Main findings}

Studies in this systematic review reported an association between abnormal PCI with preterm birth, SGA infants, low birthweight, emergency $\mathrm{CD}$, and intrauterine fetal death. Unfortunately, variation in study designs and difference in definition of abnormal PCI across studies prevents precise comparison. Our meta-analysis of four studies in this systematic review demonstrates a statistically significant increased risk of emergency $\mathrm{CD}$ in pregnancies with VCI and abnormal PCI compared to those with normal PCI with some evidence of heterogeneity.

Ebbing et al. also found an association of other adverse outcomes with $\mathrm{MCI}$, including preterm birth, NICU admission, low birth weight, emergency and elective CD [6]. Due to the lack of studies separating non-VCI into MCI and normal PCI, we could not carry out a meta-analysis of the association of MCI with these other adverse outcomes. Ebbing et al. reported that pregnancies with previous history of $\mathrm{VCI}$ were found to be at an increased risk of $\mathrm{VCI}$ and $\mathrm{MCI}$ [6]. This suggests similar etiologic factors, and supports the assumption that $\mathrm{VCI}$ and $\mathrm{MCI}$ represent a continuum of a condition that occurs as a consequence of an altered placental development [6].

Advanced maternal age, defined as maternal age of 35 and above, was significantly associated with an increased risk of VCI $[7,10,20]$. The risk of VCI was also found in some studies to be significantly increased in nulliparas $[6,8,10,20]$. Nulliparity and increasing maternal age are known risk factors for pregnancy complications. Ten of the included studies adjusted their results for the known confounders including maternal age, parity, and smoking status. Emergency CD may be caused by non-reassuring cardiotocogram (CTG) but can also be due to other indications, most commonly prolonged labor. We acknowledged the inability to adjust for different indications for emergency $\mathrm{CD}$, which may cause distortion of the observed association.

\section{Strength and limitations}

Abnormal PCI is an area of obstetrics which is not well studied or reported in the literature, possibly due to the lack of standardization of its definition and the lack of antenatal diagnosis. The strengths of our systematic review and meta-analysis include the search strategy with inclusion of conference abstracts. $\mathrm{MCI}$ and $\mathrm{VCI}$ were examined separately and in combination, and then compared with normal PCI allowing for a more precise comparison. Using the Newcastle-Ottawa Scale to evaluate the methodological quality of the individual studies, all included studies were considered good quality.

However, we acknowledge several limitations which include considerable heterogeneity between the studies. We used a random effects model to combine the results to account for the considerable heterogeneity. The meta-analysis is limited by the number of studies included, with only four studies fitting the criteria and only one outcome analyzed.

\section{Recommendations}

The diagnosis of abnormal PCI is usually made after delivery. With advances in ultrasound technology, abnormal PCI can be diagnosed antenatally. The International Society of Ultrasound in Obstetrics and Gynecology (ISUOG) guidelines for second trimester ultrasound suggest describing the placental location, its relationship with the internal cervical os and its appearance [26]. Describing the PCI site was not suggested in the ISUOG guidelines for both first and second trimester scans [26, 27]. However, identification of the PCI site whenever technically possible is recommended by the American Institute of Ultrasound in Medicine (AIUM) clinical guidelines [28].

There is a need to clarify the feasibility of routine antenatal detection of abnormal PCI using ultrasound, the optimal timing of detection and the antenatal strategies to be implemented in pregnancies diagnosed with abnormal PCI. A uniform approach with standardized definition for describing PCI would benefit future research.

\section{Conclusions}

The available evidence from this systematic review and meta-analysis suggests an association between abnormal $\mathrm{PCI}$ and emergency CD. However, further studies with comparable definitions of abnormal PCI are needed and whether antenatal identification of abnormal PCI can improve maternal and neonatal outcomes remains to be determined. 


\section{Additional files}

Additional file 1: Medline search strategy. (DOCX $14 \mathrm{~kb}$ )

Additional file 2: PRISMA checklist. (DOC $62 \mathrm{~kb}$ )

Additional file 3: Table describing excluded studies. (DOCX $16 \mathrm{~kb}$ )

\section{Abbreviations}

AIUM: American Institute of Ultrasound in Medicine; CD: Cesarean delivery; CDC: Centers for Disease Control and Prevention; Cl: Confidence interval; CTG: Cardiotocogram; ISUOG: International Society of Ultrasound in Obstetrics and Gynecology; MCl: Marginal cord insertion; NICU: Neonatal intensive care unit; OR: Odds ratios; PCl: Placental cord insertion; PRISMA: Preferred Reporting Items for Systematic Reviews and MetaAnalyses; ROBINS-I: Risk Of Bias In Non-randomized Studies of Interventions; SGA: Small for gestational age; VCl: Velamentous cord insertion

\section{Acknowledgements}

We acknowledge Isabelle Delaunois, Medical Librarian at University Hospital Limerick, for her contribution in developing the search strategy.

\section{Funding}

No funding was obtained.

\section{Availability of data and materials}

All data generated or analyzed during this study are included in this published article [and its Additional files].

\section{Authors' contributions}

KII was the first reviewer and wrote the article. AH provided statistical advice, interpreted the results, and reviewed the article. KOD reviewed and critically revised the manuscript. AC contributed to the study conception, acted as the second reviewer, and critically revised the manuscript. All authors read and approved the final manuscript.

\section{Ethics approval and consent to participate}

Not applicable.

\section{Consent for publication}

Not applicable.

\section{Competing interests}

The authors declare that they have no competing interests.

\section{Publisher's Note}

Springer Nature remains neutral with regard to jurisdictional claims in published maps and institutional affiliations.

\section{Author details}

'Obstetrics and Gynaecology Department, Graduate Entry Medical School, University of Limerick, Limerick, Ireland. Biostatistics Department, Graduate Entry Medical School, University of Limerick, Limerick, Ireland. ${ }^{3}$ Obstetrics and Gynaecology Department, University College Cork, Cork, Ireland.

Received: 22 June 2017 Accepted: 23 November 2017

Published online: 06 December 2017

\section{References}

1. Baergen RN. Pathology of the Umbilical Cord, in Manual of Pathology of the Human Placenta, Second edn. New York: Springer Science \& Business Media; 2011.

2. Yampolsky M, Salafia CM, Shlakhter O, Haas D, Eucker B, Thorp J. Centrality of the umbilical cord insertion in a human placenta influences the placental efficiency. Placenta. 2009;30(12):1058-64.

3. Benirschke K. Manual of pathology of the human placental. 2nd ed. New York: Spinger Science \& Business Media; 2011.

4. Hubinont C, Lewi L, Bernard P, Marbaix E, Debieve F, Jauniaux E. Anomalies of the placenta and umbilical cord in twin gestations. Am J Obstet Gynecol. 2015;213(4):S91-S102.
5. Nordenvall M, Sandstedt B, Ulmsten U. Relationship between placental shape, cord insertion, lobes and gestational outcome. Acta Obstet Gynecol Scand. 1988;67(7):611-6.

6. Ebbing C, Kiserud T, Johnsen SL, Albrechtsen S, Rasmussen S. Prevalence, risk factors and outcomes of Velamentous and marginal cord insertions: a population-based study of 634,741 pregnancies. PLoS One. 2013;8(7):e70380.

7. Esakoff TF, Cheng YW, Snowden JM, Tran SH, Shaffer BL, Caughey AB. Velamentous cord insertion: is it associated with adverse perinatal outcomes? J Matern Fetal Neonatal Med. 2015;28(4):409-12.

8. Raisanen S, Georgiadis L, Harju M, Keski-Nisula L, Heinonen S. Risk factors and adverse pregnancy outcomes among births affected by velamentous umbilical cord insertion: a retrospective population-based register study. Eur J Obstet Gynecol Reprod Biol. 2012;165(2):231-4.

9. Uyanwah-Akpom P, Fox $\mathrm{H}$. The clinical significance of marginal and velamentous insertion of the cord. Br J Obstet Gynaecol. 1977;84(12):941-3.

10. Eddleman KA, Lockwood CJ, Berkowitz GS, Lapinski RH, Berkowitz RL. Clinical significance and sonographic diagnosis of velamentous umbilical cord insertion. Am J Perinatol. 1992;9(2):123-6.

11. Vahanian SA, Lavery JA, Ananth CV, Vintzileos A. Placental implantation abnormalities and risk of preterm delivery: a systematic review and metaanalysis. Am J Obstet Gynecol. 2015;213(4):S78-90.

12. Wells GA, Shea B, O'Connell D, Peterson J, Welch V, Losos M, Tugwell P. The Newcastle-Ottawa scale (NOS) for assesssing the quality of nonrandomized studies in meta-analyses. Ottawa: Ottawa Hospital Research Institute.

13. Huguet A, Hayden JA, Stinson J, McGrath PJ, Chambers CT, Tougas ME, Wozney L. Judging the quality of evidence in reviews of prognostic factor research: adapting the GRADE framework. Syst Rev. 2013;2:71.

14. Burke G, Saunders J, Gabathuse T, Fahy U, Slevin J, Abu H. The significance of umbilical cord insertion in term singleton pregnancies. Am J Obstet Gynecol. 2011;204(1):S60-1.

15. Pinar H, Goldenberg RL, Koch MA, Heim-Hall J, Hawkins HK, Shehata B, Abramowsky C, Parker CB, Dudley DJ, Silver RM, et al. Placental findings in singleton stillbirths. Obstet Gynecol. 2014;123(2 Pt 1):325-36.

16. Tantbirojn P, Saleemuddin A, Sirois K, Crum CP, Boyd TK, Tworoger S, Parast MM. Gross abnormalities of the umbilical cord: related placental histology and clinical significance. Placenta. 2009;30(12):1083-8.

17. Feldman D, Koning K, Bobrowski R, Borgida A, Ingardia C. Clinical implications of prenatally diagnosed marginal placental cord insertion. Am J Obstet Gynecol. 2004;191(6):S176.

18. Hasegawa J, Matsuoka R, Ichizuka K, Otsuki K, Sekizawa A, Farina A, Okai T. Cord insertion into the lower third of the uterus in the first trimester is associated with placental and umbilical cord abnormalities. Ultrasound Obstet Gynecol. 2006;28(2):183-6.

19. Hasegawa J, Matsuoka R, Ichizuka K, Kotani M, Nakamura M, Mikoshiba T, Sekizawa A, Okai T. Atypical variable deceleration in the first stage of labor is a characteristic fetal heart-rate pattern for velamentous cord insertion and hypercoiled cord. J Obstet Gynaecol Res. 2009;35(1):35-9.

20. Heinonen S, Ryynanen M, Kirkinen P, Saarikoski S. Perinatal diagnostic evaluation of velamentous umbilical cord insertion: clinical, Doppler, and ultrasonic findings. Obstet Gynecol. 1996;87(1):112-7.

21. Suzuki S, Kato M. Clinical significance of pregnancies complicated by Velamentous umbilical cord insertion associated with other umbilical cord/ placental abnormalities. J Clin Med Res. 2015;7(11):853-6.

22. Yerlikaya G, Pils S, Springer S, Chalubinski K, Ott J. Velamentous cord insertion as a risk factor for obstetric outcome: a retrospective case-control study. Arch Gynecol Obstet. 2016;293(5):975-81.

23. Carbone J, Feldman D, Lazarus S, Borgida A. Clinical implications of prenatally diagnosed marginal placental cord insertion. Am J Obstet Gynecol. 2008;199(6):S187.

24. Boulis TS, Rochelson B, Meirowitz N, Fleischer A, Smith-Levitin M, Edelman $\mathrm{M}$, Rosen $\mathrm{L}$, Williamson A, Vohra N. Is velamentous/marginal cord insertion associated with adverse outcomes in singletons? Am J Obstet Gynecol. 2013;208(1):S79.

25. Brouillet S, Dufour A, Prot F, Feige JJ, Equy V, Alfaidy N, Gillois P, Hoffmann $P$. Influence of the umbilical cord insertion site on the optimal individual birth weight achievement. Biomed Res Int. 2014;2014:8.

26. Salomon LJ, Alfirevic Z, Berghella V, Bilardo C, Hernandez-Andrade E, Johnsen SL, Kalache K, Leung KY, Malinger G, Munoz H, et al. Practice guidelines for performance of the routine mid-trimester fetal ultrasound scan. Ultrasound Obstet Gynecol. 2011;37(1):116-26. 
27. Salomon LJ, Alfirevic Z, Bilardo CM, Chalouhi GE, Ghi T, Kagan KO, Lau TK, Papageorghiou AT, Raine-Fenning NJ, Stirnemann J, et al. ISUOG practice guidelines: performance of first-trimester fetal ultrasound scan. Ultrasound Obstet Gynecol. 2013;41(1):102-13.

28. AIUM. AIUM practice guideline for the performance of obstetric ultrasound examinations. J Ultrasound Med. 2013;32(6):1083-101.

Submit your next manuscript to BioMed Central and we will help you at every step:

- We accept pre-submission inquiries

- Our selector tool helps you to find the most relevant journal

- We provide round the clock customer support

- Convenient online submission

- Thorough peer review

- Inclusion in PubMed and all major indexing services

- Maximum visibility for your research

Submit your manuscript at www.biomedcentral.com/submit 